\title{
Plasma C-Terminal Agrin Fragment (CAF) as an Early Marker for Kidney Function in Patients with Chronic Kidney Disease
}

\author{
NARDIN S. SOLIMAN, M.Sc.*; GEHAN F. ATTIA, M.D.*; SHERIF E. EZAT, M.D.** and \\ MAHA M. HAGRAS, M.D.* \\ The Departments of Clinical Pathology* and Internal Medicine ${ }^{* *}$, Faculty of Medicine, Tanta University
}

\begin{abstract}
Background: CKD is defined by the presence of renal damage or impaired renal function for three or more months, irrespective of the cause. The presence of the damage or impaired function for at least three months is important to distinguish CKD from AKI. C-terminal Agrin Fragment (CAF) was found in the basement membrane of the kidney and cleared from circulation by glomerular filtration.
\end{abstract}

Aim of Study: To evaluate plasma level of C-terminal agrin fragment as an early detector of renal function impairment in patients with chronic kidney disease.

Methods: The study was carried on two groups Group (I): 20 healthy persons as a control group and Group (II): 60 CKD patients. Patients were selected from Internal Medicine Department, Tanta University Hospital. We excluded patients suffered from inflammatory, autoimmune, infectious disorders and malignant diseases, also patients with acute underlying illness were excluded from the study. Informed consents were taken from all participants and the privacy of the data were greatly considered. Complete clinical examination including: Body Mass Index (BMI) calculation and routine laboratory investigations including Complete Blood Count (CBC), blood urea, serum creatinine, eGFR, $24 \mathrm{~h}$ proteinuria, sodium and potassium, CRP and specific investigation: Plasma level of C-terminal Agrin Fragment (CAF) measurements by ELISA technique was done.

Results: Plasma CAF showed statistical significance increase in patients group than control healthy groups $\left(p^{<.001)}\right.$ with gradual increase in its level in progressive CKD stages. There was significant positive correlation between plasma CAF, serum creatinine and blood urea $(p<.001)$ while there was significant negative correlation between plasma $\mathrm{CAF}$ and eGFR $(p<.001)$. There was significant increase in CAF in early stage 1 CKD group compared to control group ( $p<.001)$. Plasma CAF wasn't affected by age, sex and muscle mass in contrast to creatinine which was affected by them.

Conclusion: The results of this study showed that plasma CAF was increasing with the progression of CKD stages and it was more sensitive and specific than serum creatinine, blood urea and eGFR in estimation of staging CKD. Plasma CAF also can differentiate between healthy individuals and stage

Correspondence to: Dr. Nardin S. Soliman, The Department of Clinical Pathology, Faculty of Medicine, Tanta University
$1 \mathrm{CKD}$ patients, so measurement of plasma level of CAF may represent a promising bio-marker of early kidney damage detection and progression to ESKD.

Key Words: Plasma C-terminal Agrin Fragment (Plasma $C A F)$ - Chronic Kidney Disease (CKD).

\section{Introduction}

CHRONIC Kidney Disease (CKD) is a major worldwide public health problem, with increasing incidence and prevalence. Chronic kidney disease is associated with persistent renal damage with progressive loss of renal function for a period ? three months [1]

According to the Global Burden of Disease (GBD) project, the prevalence of CKD has increased by $19.6 \%$ in the last decade and it affects more than 497 millions adults aged $>20$ years worldwide [2].

Diabetes mellitus and elevated blood pressure are the two main causes of chronic kidney disease. Many other diseases can cause damage to the kidney including: Glomerulonephritis, interstitial nephritis, congenital defects of the kidney (polycystic kidney), prolonged obstruction of the urinary tract (as stones), reflux nephropathy and some drugs as cancer therapy [3].

The disease may be asymptomatic in the early stages the symptoms don't appear till the renal function is lower than one-tenth of normal. Symptoms include: Sleep disorders, skin pallor and ecchymosis, edema, elevated blood pressure, headache, peripheral neuropathy, loss of appetite and nausea [4].

There is no cure for chronic kidney disease. Patients with CKD usually require dialysis or renal transplant at the End Stage of Renal Failure (ESRF), 
so early diagnosis of the disease is important to prevent progress and avoid complications [5].

Agrin is a Heparin Sulfate Proteoglycan (HSPG) which is present mainly in brain and in neuromuscular junction. It is also found to be a major component of Glomerular and tubular basement membrane [6]

Neurotrypsin (known as serine protease) cleaves agrin in two homologous sites called $\alpha$ and $\beta$ sites. Cleavage at $\alpha$ site generate $110 \mathrm{kDa}$ fragment (CAF110), whereas cleavage at $\beta$ site releasing a 22-kDa C-terminal fragment (CAF22). In human urine, CAF22 can be detected while CAF110 not. It may be originated from kidney or filtered from blood into urine via the glomerulum [7]

Changes in kidney function may be associated with changes in serum CAF levels as CAF can penetrate filtration barrier of the glomeruli, so CAF22 can be used as a novel marker for kidney function and it correlate with other markers as estimated Glomerular Filtration Rate (eGFR) [8].

\section{Subjects and Methods}

The present study was carried on 80 subjects; they were 41 males $(51.3 \%)$ and 39 females $(48.8 \%)$. Their age ranged from 25 to 73 years. The patients were selected from the Internal Medicine Department of Tanta University Hospital from November 2017 till November 2018.

\section{Inclusion criteria:}

The subjects of this study were classified into 2 groups:

- Group I: 20 apparently healthy person serving as control group.

- Group II: 60 patients diagnosed as chronic kidney disease.

\section{Subgroups of CKD patients:}

- Group 1 : 9 patients suffering from chronic kidney disease stage 1 .

- Group 2: 8 patients suffering from chronic kidney disease stage 2 .

- Group 3A: 9 patients suffering from chronic kidney disease stage $3 \mathrm{~A}$.

- Group 3B: 11 patients suffering from chronic kidney disease stage 3B.

- Group 4: 11 patients suffering from chronic kidney disease stage 4 .

- Group 5: 12 patients suffering from chronic kidney disease stage 5 (not initiating dialysis).

\section{Exclusion criteria:}

- All subjects included in this study were not suffered from any other systemic disease that might affect the laboratory investigations. Patients with acute illness, inflammatory, autoimmune, infectious disorders and malignant diseases.

- All participants in this study were subjected to: History taking, full clinical examination, laboratory investigations in the form of: CRP, sodium and potassium, urea and creatinine, 24 hour urine protein collection, complete blood count, eGFR and Plasma C-terminal Agrin Fragment (CAF).

\section{Sampling and laboratory investigations:}

Sampling and all laboratory investigations were done in Clinical Pathology Department, Tanta University Hospitals. CBC was performed using Advia automatic cell counter. Blood urea, serum creatinine and $\mathrm{C}$-reactive protein were performed by using Kone lab prime device, eGFR calculation by Cockroft-Gault equation, $24 \mathrm{~h}$ urine protein assay by using photometer, sodium and potassium measurement by using Rapid Chem device and Plasma C-terminal agrin fragment by ELISA technique.

\section{Statistical analysis of the data:}

For normally distributed data, values were expressed as mean \pm standard deviation and Independent Samples $t$-test and One-Way ANOVA were performed for comparison between groups. For qualitative data, Pearson's Chi square test was used to examine association between two variables. Pearson's and Spearman's rank correlations were done to test associations of the studied variables with plasma CAF. Significance was adopted at $p<0.05$ for interpretation of results of tests. All analyses were done using SPSS Version 20. Receiver Operating Characteristic curve (ROC-curve) analysis was used to find out the over all predictivity of parameter in and to find out the best cutoff value with detection of sensitivity and specificity at this cut-off value.

\section{Results}

Comparison between the studied groups showed statistical significance as regard to hemoglobin, urea, creatinine, eGFR, 24h urine proteins, CRP (Table 4). In contrary comparison showed no statistical significance as regard age, sex, BMI and WBCs count as shown in (Tables 1-4). As for plasma CAF, it was significantly higher in patients group in comparison to the control group as shown in (Table 8). In this study plasma CAF showed positive correlation with serum creatinine and 
blood urea and showed negative correlation with eGFR (Table 9), Figs. (1-3). In this study, there was no significant difference between healthy control group and CKD stage 1 patient group as regard blood urea, serum creatinine and eGFR, while there was significant increase of CAF in CKD stage 1 patient group compared to healthy control group (Table 10). This study showed that no significant relation between CAF with age, gender and BMI. While there is significant relation between serum creatinine and both age and BMI but not significant with gender (Table 11). According to ROC curve, the cut-off value of CAF for CKD is $590 \mathrm{pmol} / \mathrm{L}$ with a Sensitivity of $89 \%$ and a Specificity of $90 \%$.

Table (1): Statistical comparison of control and patients groups as regard age.

\begin{tabular}{lll}
\hline Age in years & Control group & Patients group \\
\hline Range & $25-70$ & $30-73$ \\
Mean \pm SD & $51.30 \pm 12.39$ & $54.23 \pm 10.86$ \\
$t$-test & & 1.019 \\
$p$-value & 0.316 \\
\hline
\end{tabular}

Table (2): Statistical comparison of control and patients groups as regard sex.

\begin{tabular}{clll}
\hline Sex & Control & CKD & Total \\
\hline Male: & & & \\
$\mathrm{N}$ & 12 & 29 & 41 \\
$\%$ & $60.0 \%$ & $48.3 \%$ & $51.3 \%$ \\
Female: & & & \\
$\mathrm{N}$ & 8 & 31 & 39 \\
$\%$ & $40.0 \%$ & $51.7 \%$ & $48.8 \%$ \\
Total: & & & \\
$\mathrm{N}$ & 20 & 60 & 80 \\
$\%$ & $100.0 \%$ & $100.0 \%$ & $100.0 \%$ \\
Chi-square: & & & \\
$\chi^{2}$ & & 0.823 & \\
$p$-value & & 0.366 & \\
\hline
\end{tabular}

Table (3): Statistical comparison of control and patients groups as regard BMI.

\begin{tabular}{lllll}
\hline Variables & Range & Mean \pm SD & $t$-test & $p$-value \\
\hline $\begin{array}{l}\text { Weight }(\mathrm{kg}): \\
\quad \text { Control }\end{array}$ & $55-88$ & $71.00 \pm 9.18$ & 1.83 & 0.179 \\
CKD & $50-93$ & $74.68 \pm 10.92$ & & \\
Height $(\mathrm{cm}):$ & & & & \\
Control & $160-177$ & $167.25 \pm 4.72$ & 1.925 & 0.169 \\
CKD & $160-189$ & $169.93 \pm 8.18$ & & \\
BMI $\left(\mathrm{kg} / \mathrm{m}^{2}\right):$ & & & & \\
Control & $20.45-29.76$ & $25.30 \pm 2.25$ & 2.052 & 0.156 \\
CKD & $21.0-30.9$ & $26.33 \pm 2.93$ & & \\
\hline
\end{tabular}

Table (4): Comparison of studied variables in control and patients groups.

\begin{tabular}{|c|c|c|c|c|}
\hline Variables & Range & Mean $\pm \mathrm{SD}$ & $t$-test & $p$-value \\
\hline \multicolumn{5}{|c|}{ Urea $(m g / d l):$} \\
\hline Control & $25-40$ & $35.61 \pm 4.58$ & \multirow[t]{2}{*}{33.349} & \multirow[t]{2}{*}{$0.001 *$} \\
\hline CKD & $35-177$ & $84.66 \pm 43.45$ & & \\
\hline \multicolumn{5}{|c|}{ Creat. $(\mathrm{mg} / \mathrm{dl})$ : } \\
\hline Control & $0.7-1.2$ & $1.04 \pm 0.15$ & \multirow[t]{2}{*}{18.917} & \multirow[t]{2}{*}{$0.001 *$} \\
\hline CKD & $0.9-6.5$ & $2.87 \pm 2.12$ & & \\
\hline \multirow{2}{*}{\multicolumn{5}{|c|}{$\begin{array}{l}e G F R \\
\left(\mathrm{ml} / \mathrm{min} / 1.73 \mathrm{~m}^{2}\right):\end{array}$}} \\
\hline & & & & \\
\hline Control & $95-128.5$ & $110.39 \pm 10.95$ & \multirow[t]{2}{*}{87.871} & \multirow[t]{2}{*}{$0.001 *$} \\
\hline CKD & $7.8-127$ & $45.25 \pm 32.13$ & & \\
\hline \multicolumn{5}{|c|}{$\mathrm{Na}(\mathrm{mmol} / \mathrm{L})$ : } \\
\hline Control & $138.7-143$ & $140.74 \pm 1.51$ & \multirow[t]{2}{*}{0.151} & \multirow[t]{2}{*}{0.699} \\
\hline CKD & $137.5-145$ & $140.90 \pm 1.57$ & & \\
\hline \multicolumn{5}{|c|}{$K(\mathrm{mmol} / \mathrm{L}):$} \\
\hline Control & $4.1-5.2$ & $4.68 \pm 0.31$ & \multirow[t]{2}{*}{0.704} & \multirow[t]{2}{*}{0.404} \\
\hline CKD & $4.3-5.4$ & $4.74 \pm 0.30$ & & \\
\hline \multicolumn{5}{|c|}{$C R P(m g / L):$} \\
\hline Control & $2-7$ & $4.15 \pm 1.60$ & \multirow[t]{2}{*}{28.515} & \multirow[t]{2}{*}{$0.001 *$} \\
\hline CKD & $2-42$ & $19.28 \pm 12.59$ & & \\
\hline \multicolumn{5}{|c|}{$\begin{array}{l}24 h \text { Proteinuria } \\
(\mathrm{mg} / \text { day }):\end{array}$} \\
\hline Control & 28.7-121.1 & $64.10 \pm 27.55$ & \multirow[t]{2}{*}{37.471} & \multirow[t]{2}{*}{$0.001^{*}$} \\
\hline CKD & $233.7-3570$ & $1378.22 \pm 955.87$ & & \\
\hline \multicolumn{5}{|l|}{$H b(g / d l):$} \\
\hline Control & $10.6-14$ & $12.01 \pm 0.87$ & \multirow[t]{2}{*}{79.264} & \multirow[t]{2}{*}{$0.001 *$} \\
\hline CKD & $3.2-12.2$ & $8.98 \pm 1.43$ & & \\
\hline \multicolumn{5}{|c|}{$W B C s\left(\mathrm{~mm}^{3}\right):$} \\
\hline Control & $5.1-10.5$ & $7.86 \pm 1.45$ & \multirow[t]{2}{*}{1.336} & \multirow[t]{2}{*}{0.251} \\
\hline CKD & $5.2-10.8$ & $8.36 \pm 1.71$ & & \\
\hline
\end{tabular}

Table (5): Comparison of serum creatinine level in control group versus stages of CKD among patients groups.

\begin{tabular}{lllll}
\hline & Range & Mean \pm SD & F.test & $p$-value \\
\hline Creat $(m g / d l):$ & & & & \\
Control & $0.7-1.2$ & $1.04 \pm 0.15$ & 43.162 & $0.001^{*}$ \\
Stage I & $0.9-1.27$ & $1.10 \pm 0.12$ & & \\
Stage II & $1.3-1.55$ & $1.40 \pm 0.10$ & & \\
Stage III A & $1.4-1.98$ & $1.62 \pm 0.17$ & & \\
Stage III B & $1.88-2.53$ & $2.20 \pm 0.21$ & & \\
Stage IV & $2.4-4.9$ & $3.28 \pm 0.80$ & & \\
Stage V & $2.5-6.5$ & $4.39 \pm 1.51$ & & \\
\hline
\end{tabular}

Table (6): Comparison of blood urea level in control group versus stages of CKD among patients groups.

\begin{tabular}{lllll}
\hline & Range & Mean \pm SD & F.test & $p$-value \\
\hline Urea $(m g / d l):$ & & & & \\
Control & $25-40$ & $35.61 \pm 4.58$ & 530.425 & $0.001^{*}$ \\
Stage I & $35-42$ & $38.26 \pm 2.61$ & & \\
Stage II & $43-52$ & $47.26 \pm 2.93$ & & \\
Stage III A & $49-64$ & $57.69 \pm 5.09$ & & \\
Stage III B & $66-84$ & $74.77 \pm 5.96$ & & \\
Stage IV & $90-114$ & $99.95 \pm 8.52$ & & \\
Stage V & $136.5-177$ & $159.67 \pm 12.53$ & & \\
\hline
\end{tabular}


Table (7): Comparison of eGFR in in control group versus stages of CKD among patients groups.

\begin{tabular}{lllll}
\hline & Range & Mean \pm SD & F.test & $p$-value \\
\hline $\begin{array}{l}e G F R \\
\left(\mathrm{ml} / \mathrm{min} / 1.73 \mathrm{~m}^{3}\right):\end{array}$ & & & & \\
$\quad$ Control & $95-128.5$ & $110.39 \pm 10.95$ & & \\
Stage I & $91.9-127$ & $107.93 \pm 10.59$ & & \\
Stage II & $61.41-78.4$ & $66.77 \pm 5.98$ & & \\
Stage III A & $45-58.3$ & $47.34 \pm 4.14$ & & \\
Stage III B & $30.8-39.2$ & $35.03 \pm 2.79$ & & \\
Stage IV & $15.82-29.7$ & $24.25 \pm 5.36$ & & \\
Stage V & $7.8-13.97$ & $10.96 \pm 1.73$ & & \\
\end{tabular}

Table (8): Comparison of plasma level of CAF in control group versus stages of CKD among patients groups.

\begin{tabular}{lllll}
\hline & Range & Mean \pm SD & F.test & $p$-value \\
\hline$C A F(p m o l / L):$ & & & & \\
Control & $411.7-633.2$ & $510.15 \pm 65.45$ & 155.767 & $0.001^{*}$ \\
Stage I & $534.9-709.7$ & $650.61 \pm 53.55$ & & \\
Stage II & $734.5-873.1$ & $831.79 \pm 45.41$ & & \\
Stage III A & $927.1-984.2$ & $959.10 \pm 20.23$ & & \\
Stage III B & $1008.2-1273.2$ & $1119.16 \pm 94.69$ & & \\
Stage IV & $1020.3-1920.4$ & $1519.34 \pm 264.50$ & & \\
Stage V & $2113.5-3570.2$ & $2878.33 \pm 513.64$ & & \\
\hline
\end{tabular}

Table (9): Correlation between plasma level of CAF and serum creatnine, blood urea and eGFR.

\begin{tabular}{ccc}
\hline & \multicolumn{2}{c}{ CAF } \\
\cline { 2 - 3 } & \multicolumn{1}{c}{$r$} & \multicolumn{1}{c}{$p$} \\
\hline Creat & 0.823 & $0.001^{*}$ \\
eGFR & -0.722 & $0.001^{*}$ \\
Urea & 0.931 & $0.001^{*}$ \\
\hline
\end{tabular}

Table (10): Comparison between control group and stage 1 of CKD patients group as regard urea, creatinine, eGFR and CAF.

\begin{tabular}{|c|c|c|c|c|}
\hline & Range & Mean $\pm \mathrm{SD}$ & $t$.test & $p$-value \\
\hline \multicolumn{5}{|c|}{ Urea $(\mathrm{mg} / \mathrm{dl})$ : } \\
\hline Control & $25-40$ & $35.61 \pm 4.58$ & \multirow[t]{2}{*}{2.601} & \multirow[t]{2}{*}{0.118} \\
\hline Stage I & $35-42$ & $38.26 \pm 2.61$ & & \\
\hline \multicolumn{5}{|c|}{ Creat. $(\mathrm{mg} / \mathrm{dl})$ : } \\
\hline Control & $0.7-1.2$ & $1.04 \pm 0.15$ & \multirow[t]{2}{*}{1.239} & \multirow[t]{2}{*}{0.275} \\
\hline Stage I & $0.9-1.27$ & $1.10 \pm 0.12$ & & \\
\hline \multicolumn{5}{|c|}{$\begin{array}{l}e G F R \\
\left(\mathrm{ml} / \mathrm{min} / 1.73 \mathrm{~m}^{2}\right):\end{array}$} \\
\hline Control & $95.0-128.4$ & $110.39 \pm 10.95$ & \multirow[t]{2}{*}{0.318} & \multirow[t]{2}{*}{0.577} \\
\hline Stage I & $91.9-127$ & $107.93 \pm 10.59$ & & \\
\hline \multicolumn{5}{|c|}{$C A F(p m o l / L):$} \\
\hline Control & 411.7-633.2 & $510.15 \pm 65.45$ & \multirow[t]{2}{*}{31.690} & \multirow[t]{2}{*}{$0.001^{*}$} \\
\hline Stage I & 534.9-709.7 & $650.61 \pm 53.55$ & & \\
\hline
\end{tabular}

Table (11): Comparison between plasma level of CAF and serum creatinine as regard to age, gender and BMI among studied groups.

\begin{tabular}{lcclccccc}
\hline & \multicolumn{2}{c}{ Age } & & \multicolumn{2}{c}{ Gender } & & \multicolumn{2}{c}{ BMI } \\
\cline { 2 - 3 } \cline { 7 - 8 } & $r$ & $p$ & & $r$ & $p$ & & $r$ & $p$ \\
\hline CAF & 0.135 & 0.324 & & -0.208 & 0.298 & & 0.118 & 0.412 \\
Creat & 0.515 & $0.001 *$ & & -0.327 & 0.108 & & 0.437 & $0.008 *$ \\
\hline
\end{tabular}

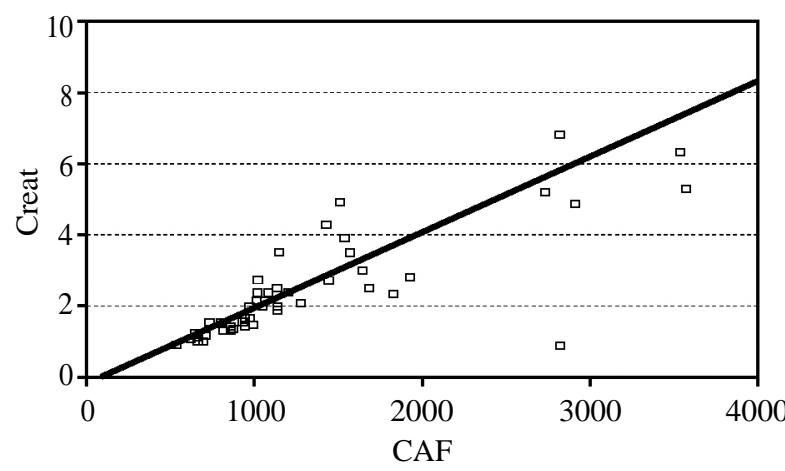

Fig. (1): Shows positive correlation between plasma CAF and serum creatinine with the progression of CKD.

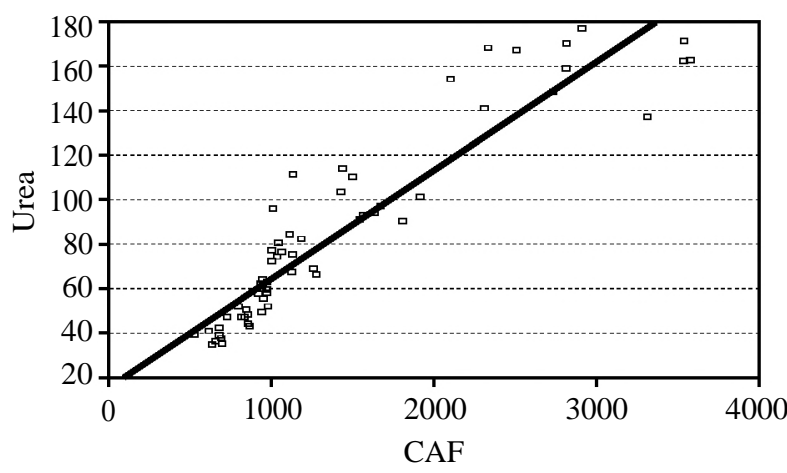

Fig. (2): Shows positive correlation between plasma CAF and blood urea with the progression of CKD.

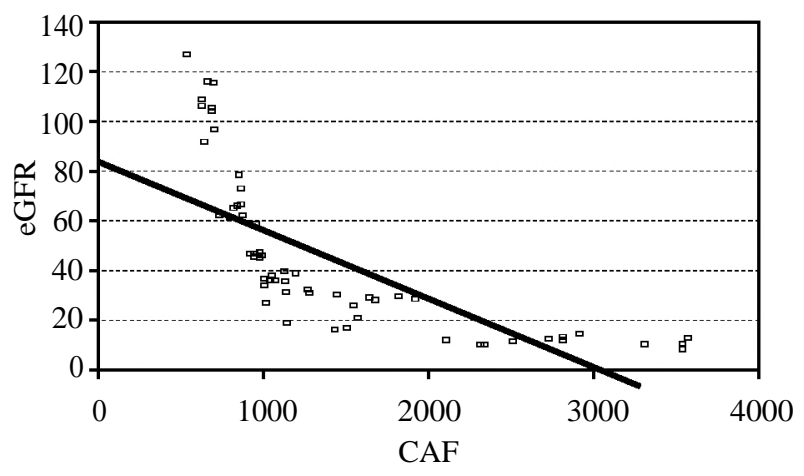

Fig. (3): Shows negative correlation between plasma CAF and eGFR with the progression of CKD.

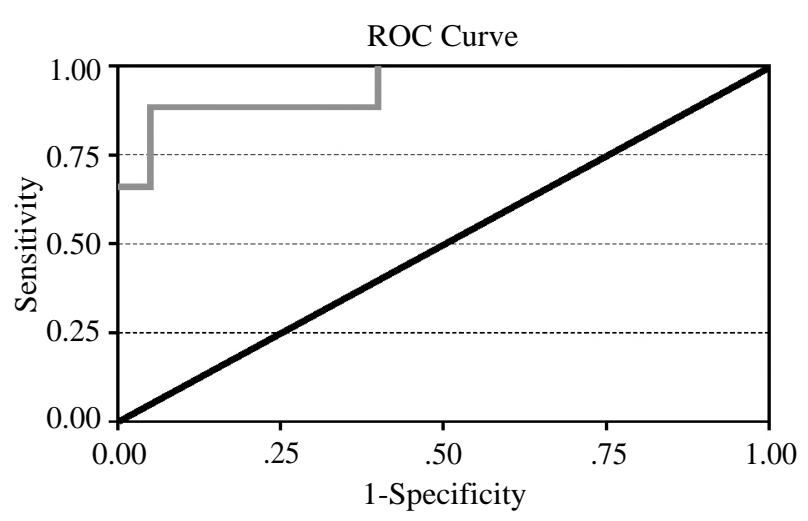

Fig. (4): Receiver Operating Characteristics (ROC) analysis of plasma CAF for predicting CKD. 


\section{Discussion}

Chronic Kidney Disease (CKD) is a major and growing challenge for health care systems. The prevalence rates of CKD appear to be increasing globally and are expected to increase further as a result of ageing populations and increased prevalence of Type II diabetes mellitus. Chronic Kidney Disease (CKD) is diagnosed when there is evidence for renal injury and/or decreased kidney function $\left(\mathrm{GFR}<60 \mathrm{ml} / \mathrm{min} / 1.73 \mathrm{~m}^{2}\right)$ present $>3$ months. CKD is characterized by accumulation of metabolic waste products in blood, electrolyte abnormalities, anemia and mineral and bone disorders [9]

CKD is usually asymptomatic, but it is detectable. There is evidence that treatment can delay or prevent the CKD progression, reduce or prevent the development of complications [10].

Agrin is a Heparin Sulfate Proteoglycan (HSPG) with a core protein size about $220 \mathrm{kDa}$ which is considered as an important organizer of postsynaptic differentiation at Neuromuscular Junctions (NMJs). Agrin expression is found to be highest in the glomerular basement membranes of the kidneys where it can be involved in membrane filtration and permeability [11].

So, this study was aimed to evaluate plasma level of C-agrin fragment in relation to kidney function in patients with CKD to throw more light on its clinico-pahological significance in such cases.

This study was conducted in Clinical Pathology Department and Internal Medicine Departments in Tanta University Hospital. They were selected from out-patients clinics of Internal Medicine Departments, Tanta University Hospital.

This study was conducted on 80 subjects classified as follows:

- Group I: 20 apparently healthy person serving as control group.

- Group II: 60 patients diagnosed as chronic kidney disease.

Group II were subdivided into 5 stages according to the Kidney Disease Improving Global Outcomes (KDIGO) 2013 Clinical Practice.

In this present study, no significant variation was found as regard sex in CKD patients group.

This was in agreement with Po-Ya [12] who reported no difference between man and women in CKD patients. Both male and female patients have the common risk factors such as poor control of glycemia, blood pressure and proteinuria. $\mathrm{He}$ explained that hyperglycemia has been reported as a crucial risk factor for nephropathy with CKD progression in both male and female.

However, Ana C R [13] reported that men had higher risk of CKD progression and death compared with women. It was related to the effect of androgen that predispose to hypertension with reduced renal function.

In this study, the age of CKD patients ranged from 30 to 73 years which is more or less similar to that reported by Dan Yu [14], but a lower age range for CKD patients was detected in another study done by Jha [15], in which the age range of their CKD patients was 20 to 50 years.

The present study showed that there was no significant variation between CKD patients group and control as regard weight, height and BMI.

This is in agreement with Tian-J [16] who reported that $\mathrm{BMI}$ is not significant with $\mathrm{CKD}$, so the definition and classification of obesity among patients with CKD should be intensively redetermined, because misdiagnosis can lead to inappropriate clinical decisions and might deteriorate patients' prognosis.

In contrast, Sojib B [17] reported that significant association between BMI and CKD. This could be demonstrated by the fact that CKD patients usually lose their weight as CKD patients usually develop anemia and their nutritional status can also in decline.

Concerning serum creatinine and blood urea levels, it was found in this study that they were significantly increased in CKD patients with progression of the disease. ( $p$-value $<0.001$ ).

This is in agreement with Divya P and Anil K [18] who reported that there is a significant positive relationship between serum creatinine and blood urea levels with renal disease. Creatinine is filtered by glomerulus and thus, serum creatinine level is considered as an indirect measure of glomerular filtration. Diminishing of glomerluar filtration rate results in rise of plasma concentrations of serum creatinine. Also, when the kidneys are unable to excrete urea, there is an increase in the blood urea level.

The present study also showed significant decline in estimated glomerular filtration rate in CKD patient group compared to control group which 
was associated with disease progression. ( $p$-value $<0.001)$.

This was in agreement with Ching-W [19] who reported progression of Chronic Kidney Disease (CKD) is manifested by decreasing estimated Glomerular Filtration Rate (eGFR). Absolute annual decline rate of eGFR is a useful therapeutic target to control CKD progression. Specifically, individuals with eGFR decline rate over $3 \mathrm{ml} / \mathrm{min} / 1.73$ $\mathrm{m} 2 /$ year require an intense focus on renal care.

In the present study, it was found that there was significant elevation in proteinuria in CKD patients group compared with healthy control group. ( $p$-value $<0.001)$.

This is in agreement with Paolo $\mathrm{C}$ and Giuseppe $\mathrm{R}$ [20] who reported that renal disease is associated with hypertrophy and the tone of afferent arterioles drops by a greater degree than that of efferent ones. These changes increase glomerular capillary hydraulic pressure and lead to more filtrate formed per nephron. These changes result in nephron loss with subsequent injury of remaining intact nephrons.

In the present study, it was found that there was significant elevation in CRP titre in patients group compared with healthy control group. ( $p$ value $<0.001)$.

This was in agreement with Oluseyi A [21] who demonstrated that high CRP titre was significantly higher in the CKD group compared to the controls who did not have CKD.

This study showed that inflammation as measured by CRP level increases with declining renal function in CKD patients. It is due to chronic inflammation present in chronic kidney disease which leads to increase the amount of inflammatory markers.

In the present study, it was found that there was significant decline of hemoglobin level in CKD patients group compared with healthy control group. ( $p$-value $<0.001$ ).

This was in agreement with Ming-H [22] who reported that decreasing of the hemoglobin level with progression of CKD. It is a multifactorial process because relative erythropoietin deficiency, shortened erythrocyte survival, disordered iron homeostasis and uremic-induced inhibitors of erythropoiesis.

The present study showed that there is no significant difference between CKD patient group and control group as regard serum sodium and potassium levels. ( $p$-value $<0.001$ ).

In contrast Nicholas I [23] reported that higher serum sodium concentration is associated with the progression of CKD, independently of other established risk factors. There was an association between higher serum sodium concentration and subsequent eGFR decline, a $5 \mathrm{mmol} / \mathrm{L}$ increase in baseline serum sodium was associated with a loss in eGFR of $7.4 \mathrm{~mL} / \mathrm{min} / 1.73 \mathrm{~m}^{2}$ over 6 years in individuals with established CKD. Also, in contrast to the present study, Nakhoul G [24] reported that Hypokalemia and hyperkalemia are often noted in Chronic Kidney Disease (CKD) patients. Serum potassium levels $<4.0$ and $>5.0 \mathrm{mmol} / 1$ were associated with higher mortality but not with ESRD.

The present study showed no significant variation between CKD patient group and control group as regard WBCs count as infectious and inflammatory disorders were excluded from this study.

In contrast, Yohei A [25] reported that elevated white blood cell count has a relationship with Chronic Kidney Disease (CKD) progression. However, elderly patients commonly fail to develop a high WBC count in response to several diseased states and may instead present a low WBC count. They hypothesized that low WBC count, in addition to high WBC count, is associated with CKD progression in the elderly. Toxic metabolic wastes retained in uremic states promote cytokine accumulation and persistent systemic inflammation resulting in elevation of WBC count. On the other hand, low lymphocyte counts often reflect immunosuppression that occurs with aging.

In the present study, plasma level of CAF was found to be significantly increased in CKD patient group compared to control group ( $p$-value $<0.001$ ).

This finding was in agreement with Steubl D [26] who found that agrin is highly expressed in the kidney where it is the major heparan sulfate proteoglycan in the glomerular and tubular basement membrane and a component of the extracellular matrix in CKD patients. They reported that the circulating level of CAF gradually increases with declining of renal function and when patients reach end-stage renal disease, CAF levels can be up to 12 fold-above its normal range.

The present study showed that the plasma CAF has been identified in the peripheral blood of healthy subjects. Low level of circulating CAF was found in healthy group compared to its level in CKD group. 
In addition, the present study showed that plasma CAF concentrations had been gradually increased with progressive stages of CKD. Also, with comparing adjacent stages of CKD a significant difference could be detected in all stages of CKD from stage I to V ( $p$-value <0.001).

In present study, plasma CAF concentration showed significant positive correlation with other renal biomarkers as, serum creatinine and blood urea. Additionally, CAF showed the negative correlation with eGFR.

This is in agreement with Drey [27] who demonstrated that CAF level was strongly associated and comparable to established renal function parameter (creatinine and urea) in critical ill patients.

The kinetics of the present study suggested that CAF was cleared similarly to creatinine, mainly by the glomerulus. However, in contrast to creatinine, no factors were observed to affect plasma CAF concentration as age, sex, or BMI.

The present study showed that no detectable difference between both control group and stage 1 of CKD patient group as regards measurement of serum creatinine, blood urea and eGFR.

On the other hand, the present study showed that there was a detectable difference in CAF concentration between both control group and stage 1 of CKD patients, so measurement of CAF plasma level can differentiate between healthy control and CKD stage 1 .

According to this finding, CAF may represent a promising bio-marker of early prediction of the kidney damage and contribute in starting early treatment of CKD patients, so CAF is useful in prevention of progression to ESKD.

In addition, the present study showed that CAF values were associated with CKD with a sensitivity of $89 \%$ and a specificity of $90 \%$. It also found that CAF accuracy for predicting CKD is $90 \%$.

CAF measurement was found to be more sensitive, specific as well as more accurate than serum creatinine, blood urea level and eGFR measurement in predicting as well as following-up of CKD patients.

Recent studies showed that CAF was likely cleared from circulation by the glomerular filtration and subsequent endocytosis in the proximal tubules in their animal experiments. Therefore, the possible explanations of this finding were that neuromus- cular injury that occurred in patients with renal disease is associated with decreased renal clearance with subsequent elevation of plasma level of CAF concentration and thereby facilitate the detection of reduced kidney function by elevated CAF22 serum levels [28].

Also, Dominik S [29] reported that serum levels of C-terminal Agrin Fragment (CAF) correlated with kidney function and reacted more rapidly to changes in renal function than creatinine. Due to its greater molecular mass, the serum CAF concentrations were less affected by dialysis than creatinine or urea.

In addition, Vasilios D [30] reported that although plasma CAF reflect renal function and was highly associated with eGFR and proteinuria at several time points, it predicted loss of renal function also at early stage of CKD patients in the absence of proteinuria. So, CAF, a novel kidney function and injury biomarker, was associated with subsequent renal function loss irrespective of proteinuria at baseline. The association was strong and was not altered by several risk factors as muscle mass or diet. Plasma CAF levels provide important information on the long-term outcome of CKD patients, which exceed a simple reflection of glomerular filtration rate and proteinuria.

\section{Limitations of the study:}

There were certain limitations of this study:

- Only a small number of patients were included.

- We excluded patients who had acute underlying illness, evidence of malignancy, autoimmune diseases, systemic inflammatory conditions and advanced liver disease.

- High cost of ELISA kit.

- The effects of more factors such as hormone levels on plasma CAF are not known.

\section{Conclusion:}

- Plasma level of CAF is significant higher in CKD patients and it is gradually increasing with the progression of CKD stages.

- Plasma CAF is positively correlated with serum creatinine and blood urea. While, CAF is negatively correlated with eGFR.

- Plasma CAF level shows significant increase in CKD patients stage 1 subgroup compared to healthy control group.

- CAF isn't affected by age, sex or MBI in contrast to creatinine which was affected by them. 
- CAF sensitivity was $89 \%$, specificity $90 \%$ and accuracy $90 \%$ in predicting chronic kidney disease.

- Thus plasma CAF may represent a new bio marker for the diagnosis of CKD particularly in the early stage of the disease.

\section{Recommendations:}

It is recommended to:

- Screening for chronic kidney disease in adults of any age who have risk factors like obesity, dyslipidemia and first degree family history.

- There is a need to improve the chronic kidney disease patients and general populations awareness of CKD complications, risk factors and the importance of life style modifications.

- The plasma CAF should be measured annually in patients who are risky to develop CKD.

- Further researches are required to investigate other factors affecting the plasma level of Cterminal Agrin Fragment (CAF) across a broader range of populations.

\section{References}

1- DELLES C. and VANHOLDER R.: Chronic kidney disease. Clinical science, 13: (3), p. 225-6, 2017.

2- THOMAS B.: Global cardiovascular and renal outcomes of reduced GFR. J. Am. Soc. Lancet, 379 (9811): 16580, 2017.

3- LEVEY A.S. and CORESH J.: Chronic kidney disease. Lancet, 379: 165-80, 2012.

4- BROWN M.A.: CKD in elderly patients managed without dialysis: Survival, symptoms, and quality of life. Clin. J. Am. Soc. Nephrol., 10: pp. 260-8, 2015.

5- OLIVIER J., DONAL J., JAMES RITCHIE, et al.: Early chronic kidney disease: Diagnosis, management and models of care. Nat. Rev. Nephrol., 11 (8): 491-502, 2016.

6- FRISCHKNECHT R., CHANG K.J., RASBAND M.N., et al.: Neural ECM molecules in plasticity. Prog Brain Res 214: 81-100. Axonal and synaptic homeostatic, 2014.

7- STEPHAN A., MATEOS J.M., KOZLOV S.V., et al.: Neurotrypsin cleaves agrin locally at the synapse. FASEB J., 22: 1861-73, 2008.

8- STEUBL D., HETTWER S., DAHINDEN P., et al.: C terminal Agrin Fragment (CAF) as a serum biomarker for residual renal function in peritoneal dialysis patients. Int. Rol. Nephrol., 47: 31-396, 2015.

9- ANGELA C., EVI V., RACHAEL L., et al.: Chronic Kidney Disease. Lancet, 389 (10075): 1238-52, 2017.

10- EMMA J., GERALDINE, SIMON, et al.: Patients' Experiences After CKD Diagnosis: A Meta-ethnographic Study and Systematic Review. Am. J. Kidney Dis., 70 (5): 65665, 2017.
11- AREZOO D., MONIKA H., MARTA F., et al.: The CTerminal Fragment of Agrin (CAF), a Novel Marker of Renal Function, Is Filtered by the Kidney and Reabsorbed by the Proximal Tubule. PLoS One, 11 (7): e0157905, 2017.

12- PO-YA, LI-NIEN, YUH-FENG, et al.: Risk factors of gender for renal progression in patients with early chronic kidney disease. Medicine (Baltimore), 95 (30): e4203, 2016.

13- ANA C.R., WEI Y., DAOHANG S., et al.: Sex-Related Disparities in CKD Progression. J. Am. Soc. Nephrol., 30 (1): 137-46, 2019.

14- DAN YU, HAI-XIA LI, YI LI, et al.: The Reference Intervals for Serum C-Terminal Agrin Fragmentin Healthy Individuals and as a Biomarker for Renal Function in Kidney Transplant Recipients. Journal of Clinical Laboratory Analysis, 31: e22059, 2017.

15- JHA V., GRACIA-GRACIA G., ISEKI K., et al.: Chronic kidney disease: Global dimension and perspectives. The Lancet, 382: (9888): 260-72, 2013.

16- TIAN J., CAI M., MEI Y., e al.: Relationship between body mass index and renal function deterioration among the Taiwanese chronic kidney disease population. Scientific Reports volume 8, Article number: 6908, 2018.

17- SOJIB B., NAZNIN H., MUNTASIRUR R., et al.: Associations between Body Mass Index and Chronic Kidney Disease in Type 2 Diabetes Mellitus Patients: Findings from the Northeast of Thailand. Diabetes Metab. J., 42 (4): 330-7, 2018.

18- DIVYA P. and ANIL K.: Assessment and Correlation of Urea and Creatinine Levels in Saliva and Serum of Patients with Chronic Kidney Disease, Diabetes and HypertensionA Research Study. J. Clin. Diagn. Res., (10): ZC58-ZC62, 2016.

19- CHING W., I WEN T.,1 HUNG C., et al.: Longitudinal change in estimated GFR among CKD patients: A 10year follow-up study of an integrated kidney disease care program in Taiwan. PLoS One, 12 (4): e0173843, 2017.

20- PAOLO C. and GIUSEPPE R.: Pathophysiology of proteinuria and its value as an outcome measure in chronic kidney disease. Br. J. Clin. Pharmacol., 76 (4): 516-23, 2013.

21- OLUSEYI A., ENAJITE I., CHIMEZIE G., et al.: Serum $\mathrm{C}$-reactive protein levels in pre-dialysis chronic kidney disease patientsin southern Nigeria. Ghana Med. J., 50 (1): 31-8, 2016

22- MING H., JYH G., YU W., et al.: High Fibroblast Growth Factor 23 Levels Associated With Low Hemoglobin Levels in Patients With Chronic Kidney Disease Stages 3 and 4. Medicine (Baltimore), 95 (11): e3049, 2016.

23- NICHOLAS I., REBECCA J., VIPULA D., et al.: Serum sodium concentration and the progression of established chronic kidney disease. Journal of Nephrology, Volume 32, Issue 2, pp. 259-64, 2019.

24- NAKHOUL G., HUANG H., ARRIGAIN S., et al.: Serum Potassium, End-Stage Renal Disease and Mortality in Chronic Kidney Disease. Am. J. Nephrol., 41: 456-63, 2015.

25- YOHEI A., EIICHIRO K., SOICHIRO I., et al.: Low white blood cell count is independently associated with chronic 
kidney disease progression in the elderly: The CKDROUTE study. Volume 22, Issue 2, pp. 291-8, 2018.

26- STEUBL D., ROOS M., HETTWER S., et al.: Plasma total C-terminal agrin fragment (tCAF) as a marker for kidney function in patients with chronic kidney disease. Clin. Chem. Lab. Med., 54: 1487-95, 2016.

27- DREY M., BEHNES M., KOB R., et al.: C-terminal agrin fragment $(\mathrm{CAF})$ reflects renal function in patients suffering from severe sepsis or septic shock. Clin. Lab., 61: 69-76, PMID, 2015.

28- DARYADEL A., HAUBITZ M., FIGUEIREDO M., et al.: The C-terminal fragment of agrin (CAF), a nove marker of renal function, is filtered by the kidney and reabsorbed by the proximal tubule, 11: e0157905, 2016.

29- DOMINIK S., STEFAN HETTWER, PIUS D., et al.: Cterminal agrin fragment (CAF) as a serum biomarker for residual renal function in peritoneal dialysis patients. International Urology and Nephrology, Volume 47, Issue 2, pp. 391-6, 2015.

30- VASILIOS D., AREZOO D., STEFANOS R., et al.: CTerminal Fragment of Agrin (CAF): A Novel Marker for Progression of Kidney Disease in Type 2 Diabetics. PLoS One, 10 (12): e0143524, 2015.

\title{
دراسلة مستوى السى تيرمنال فرجمنت من الاجرين فى البلازما كدلالة مبكرة

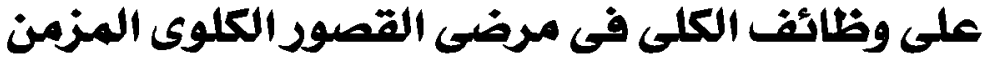

\author{
تقذت الدراسة على مجموعتين:

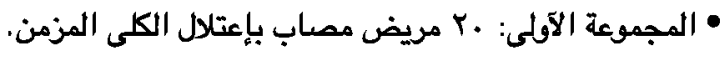 \\ • المجموعة الثانية: .7 شخص آصحاء كمجموعة مراقبة. \\ تم تقسيم المجموعة الآولى إلى خمسة مجموعات: \\ • المجموعة الآولى : تتكن من 9 مرضى في المرحلة الآولى من الإعتلال الكلوى المزمن. \\ • المجموعة الثانية: تتكون من 1 مرضى فى المرحلة الثانية من الإعتلال الكلوى المزمن. \\ • المجموعة الثالثة (آ): تتكن من 9 مرضى فى المرحلة الثائة من الإعتلال الكلىى المزمن. \\ • المجموعة الثالثة (ب): تتكون من $1 /$ مريض فى المرحلة الثالثة من الإعتلال الكوىى المزمن. \\ • المجهوعة الرابعة: تتكن من لالمريض فى المرحلة الرابعة من الإعتلال الكلوى المزمن. \\ • المجموعة الخامسة: تتكن من با مريض فى المرحة الخامسة من الإعتلال الكلوى المزمن.

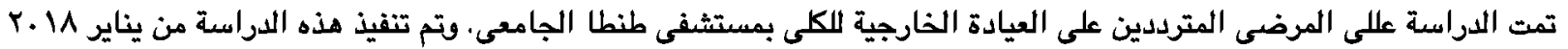

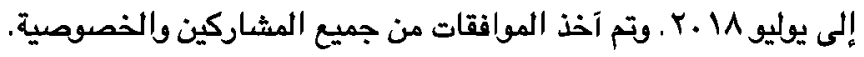

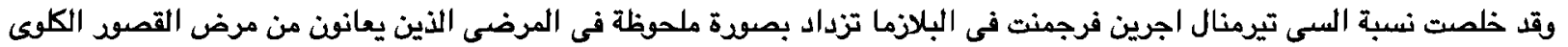

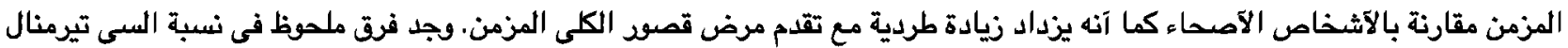

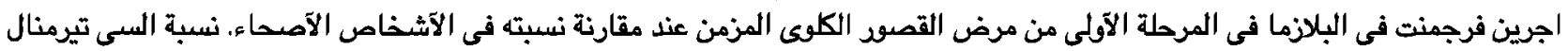

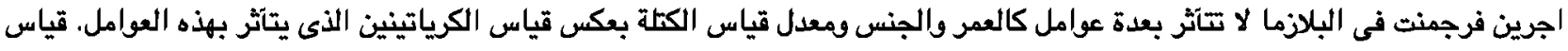

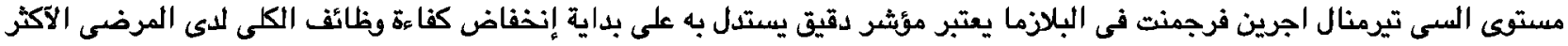

